\title{
RV Reducer Dynamic Performance Test Bed Design in Closed Power Flow
}

\author{
Wen-bo $\mathrm{Fu}^{1}$, Chang-sheng $\mathrm{Ai}^{1,{ }^{*},}$, Cheng-long Tang ${ }^{2}$, \\ Yong-shun Yang ${ }^{2}$, Guo-ping $\mathrm{Li}^{1}$ and Hong-hua Zhao ${ }^{1}$ \\ ${ }^{1}$ School of Mechanical Engineering, University of Jinan, Jinan 250022, China \\ ${ }^{2}$ Shandong Shuaike Machinary Ltd, Weifang 261206, China \\ *Email: me_aics@ujn.edu.cn
}

Keywords: RV reducer, dynamic performance test, closed power flow

Abstract. On the basis of the comparison between the open power flow pattern and the closed power flow pattern, a dynamic performance test bench of RV reducer with closed power flow is proposed. It is used to test the RV reducer dynamic performance, such as wear test and fatigue test. Test bench structure uses back-to-back energy feedback mode. According to the measurement parameters, the torque speed sensor is used to collect the relevant data. The loading device is used to apply different load torque. Under the premise of ensuring the accuracy of the test, the test efficiency is improved, and the energy consumption of the test bench is effectively reduced.

\section{Introduction}

Reducer dynamic and static performance test system test bench can be divided into two types based on the transfer of energy is recycled or not in the experimental process: open power flow and closed power flow. In the open power flow measurement and control system, the drive unit and the loading unit consume a large amount of energy, and could not achieve energy recycling. Energy consumption is larger, not suitable for the test experiment for a long time to run [1]. Therefore, about the dynamic transmission efficiency test, the angle transmission error test and so on under static condition for the reducer, the test that do not need a long time to run can be used to open power flow structure.

Compared with the open, closed power flow structure in the utilization of energy efficiency to be better, and for more energy consuming, longer operation time test, its running cost is lower and more efficient [2]. Therefore, about the wear test, fatigue test and so on need a long time to run the test, the closed structure is more efficient and reliable, and the energy consumption is lower. For the fatigue test and wear test of the RV reducer dynamic performance test whose energy consumption is larger and the running time is longer, this article puts forward a new design of dynamic performance test station closed based on power flow, and the principle is analyzed.

\section{Principle of power closed test bed}

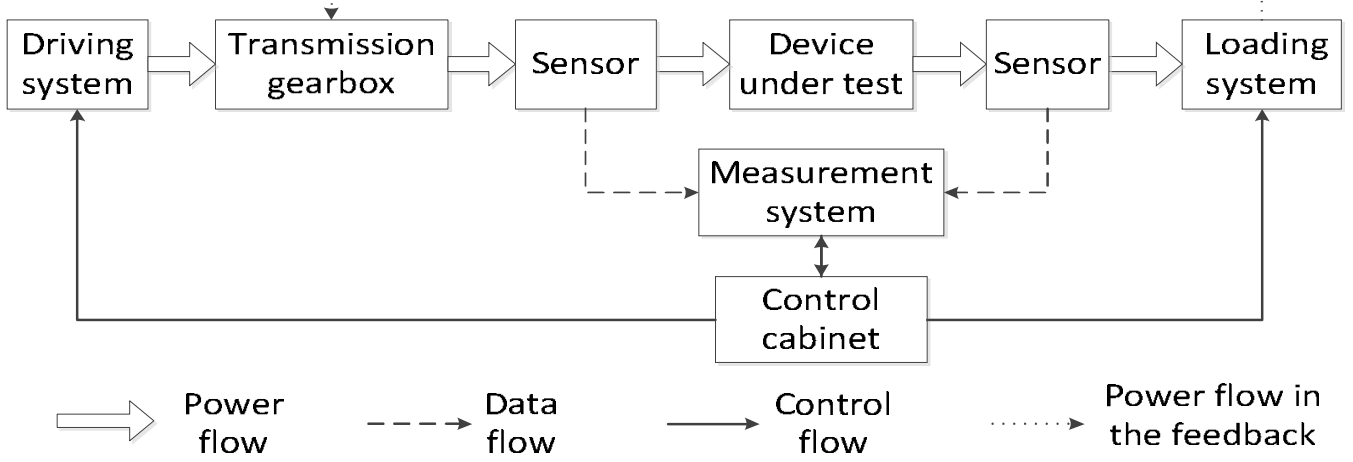

Fig. 1 The structure schematic diagram of the closed power flow test bench 
The structure schematic diagram of the closed power flow test bench is shown in Fig.1, compared with the open power flow, the transmission gear box is added in the structure. In this test system[3], the energy provided by drive system through the transmission gear box, the input shaft detection device, the measured speed reducer, the output shaft detection device, loading device, and at last energy back to gear box. Compare with open power flow, this way can complete the effective and stable load [4], and can effectively use the energy and save a lot of energy. It is suitable for long run test, such as the wear test, fatigue life experiment and so on.

\section{System overall structure}

In view of the fatigue test and wear test need long time and bigger energy dissipation, we put forward a new kind of testing system based on closed power flow design. Its overall structure design as shown in Fig.2.

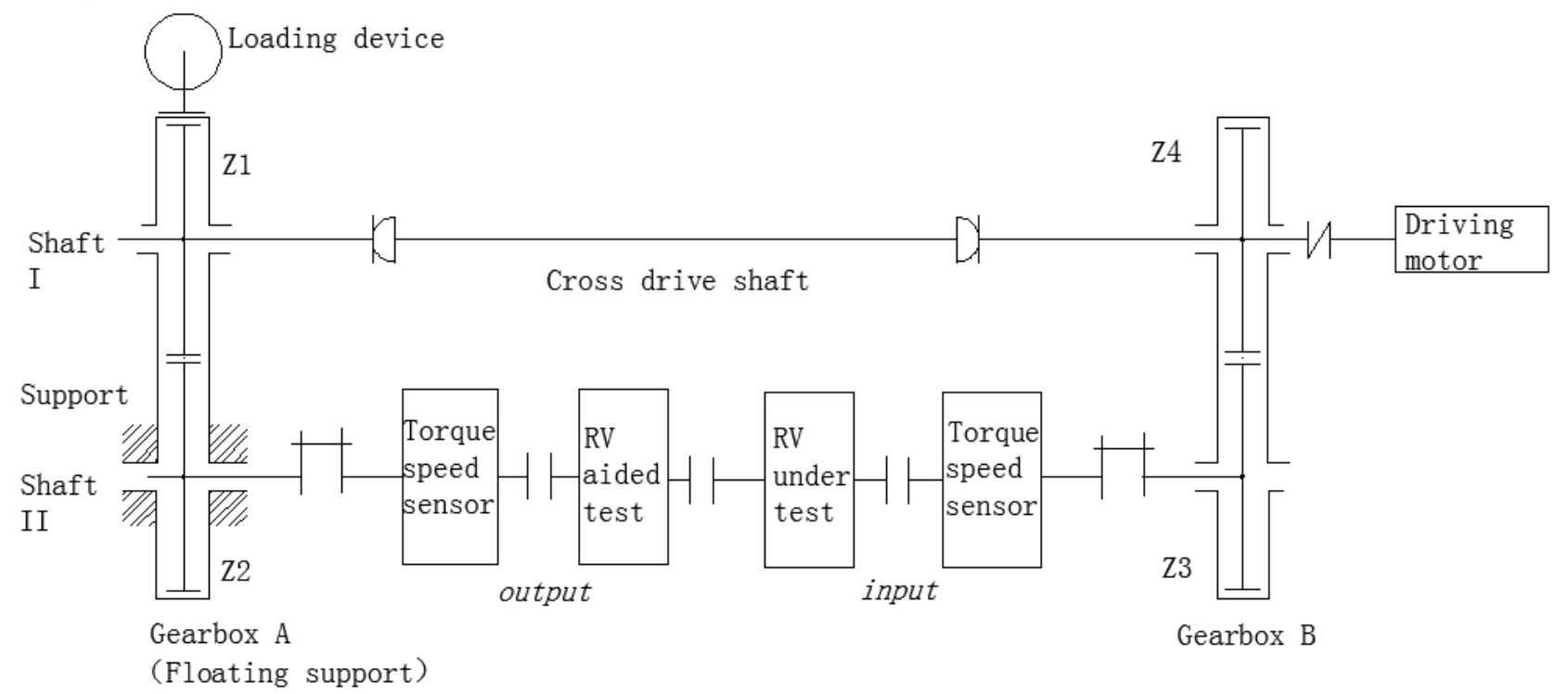

Fig. 2 Structure diagram of RV reducer test bed closed power flow

Compared to open power flow model test rig, the structure of closed power flow model test rig has two more gear transmission who's ratio is 1 . The whole test bench is driven by a electromotor, and connect with fixed gear box B. Another gear box A is floating supporting, can revolves around supporting C. Using the manual loading scale pan loading way. In the process of test, the reducer to be measured can realize loading and unloading smoothly. Shaft I is connected two correspond shaft of gear box with cross universal coupling, each test piece of shaft II is connected with rigid coupling. The measured speed reducer and the auxiliary reducer adopts back-to-back mounting in shaft II, by driving and loading fatigue tests can be carried out on high power test for a long time. Torque speed sensor is placed in both ends of test gear reducer, monitoring torque and speed in this experiment.

\section{Analysis of flow direction of power flow and loss power}

The power flow direction of the whole closed power flow system is determined by the driving device and the loading direction [5]. The flow direction begin from the drive device, then flow to the gear box, and according to the meshing order and connections, through different system installation in turn, eventually flows back to the gear box. The specific flow direction can be determined through the relationship between the active gear and driven gear.

The analysis as shown in Fig.3, the system power flow flows clockwise according to the direction of Z4 - Z3 - shaft I- Z2 - Z1 - shaft II-Z1. According to the relationship between steering and torque of external meshing gear drive gear and driven gear, we know that if only one side change between steering and torque but the other is unchanged, then the power flow change. If the two change at the same time, the power flow will not change. 


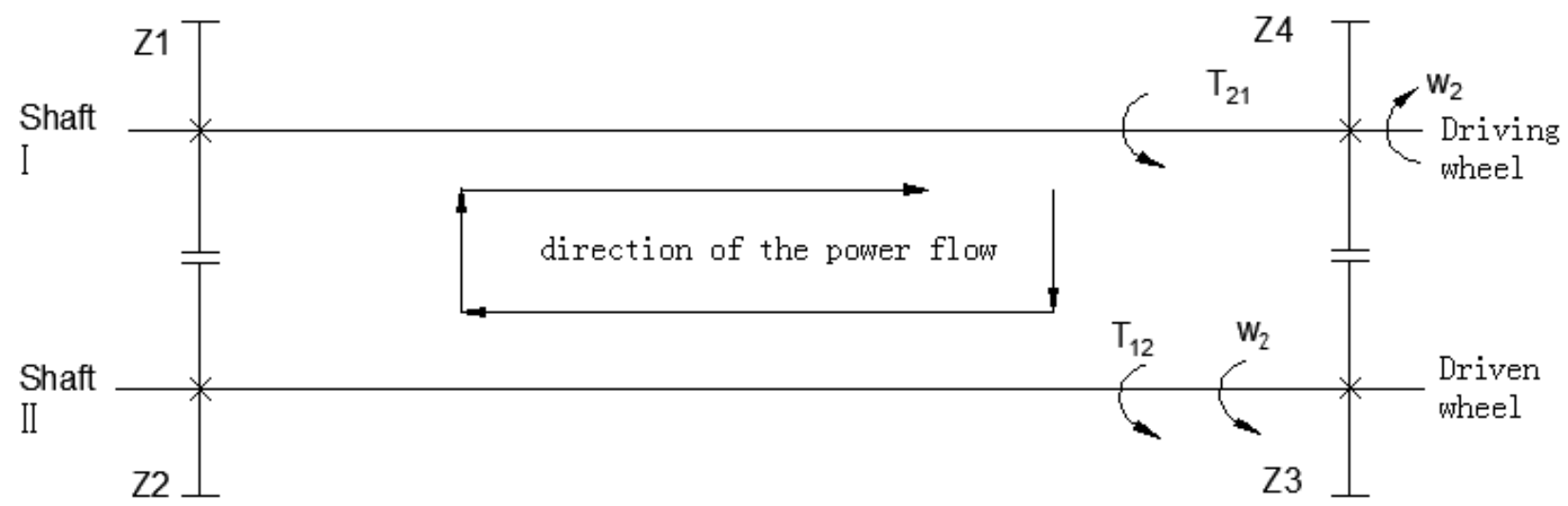

Fig. 3 Flow direction of power flow in a closed system

Closed power in the system will not damage with the flow of energy [6]. As shown in Fig.4, if the power flows according to the direction of gearbox B - shaft III - the device under test - aided test device - shaft II - swing box A - shaft I - gearbox B (Z4), the loss power provided by the drive means to the system will be lost in the friction pairs with the flow of energy. In other words, the driving device only needs to compensate for the loss of friction power during system operation.

As shown in Fig.4, the drive motor connect gearbox B, at this time the gear Z4 inside the gear box B exist closed power $P_{\mathrm{f}}$, then its effective power is $P_{\mathrm{f}}+P_{\mathrm{s}}$. After the transmission and friction loss in gearbox B, the energy from the gearbox output to shaft III, its power turn into $P_{\mathrm{f}}+P_{\mathrm{s}^{-}} P_{\mathrm{b}}$. Through the drive shaft III, measured the RV reducer, auxiliary test gear reducer, transmission shaft II, energy incoming floating gearbox A. After the internal gear transmission and the friction loss, when the energy reaches shaft I, the power turn into $P_{\mathrm{f}}+P_{\mathrm{s}^{-}}\left(P_{\mathrm{a}}+P_{\mathrm{b}}\right)$. The total loss of power in the transmission process is $P_{\mathrm{a}}+P_{\mathrm{b}}$. This part is compensated by the output of the driving motor, namely to compensate the friction loss.

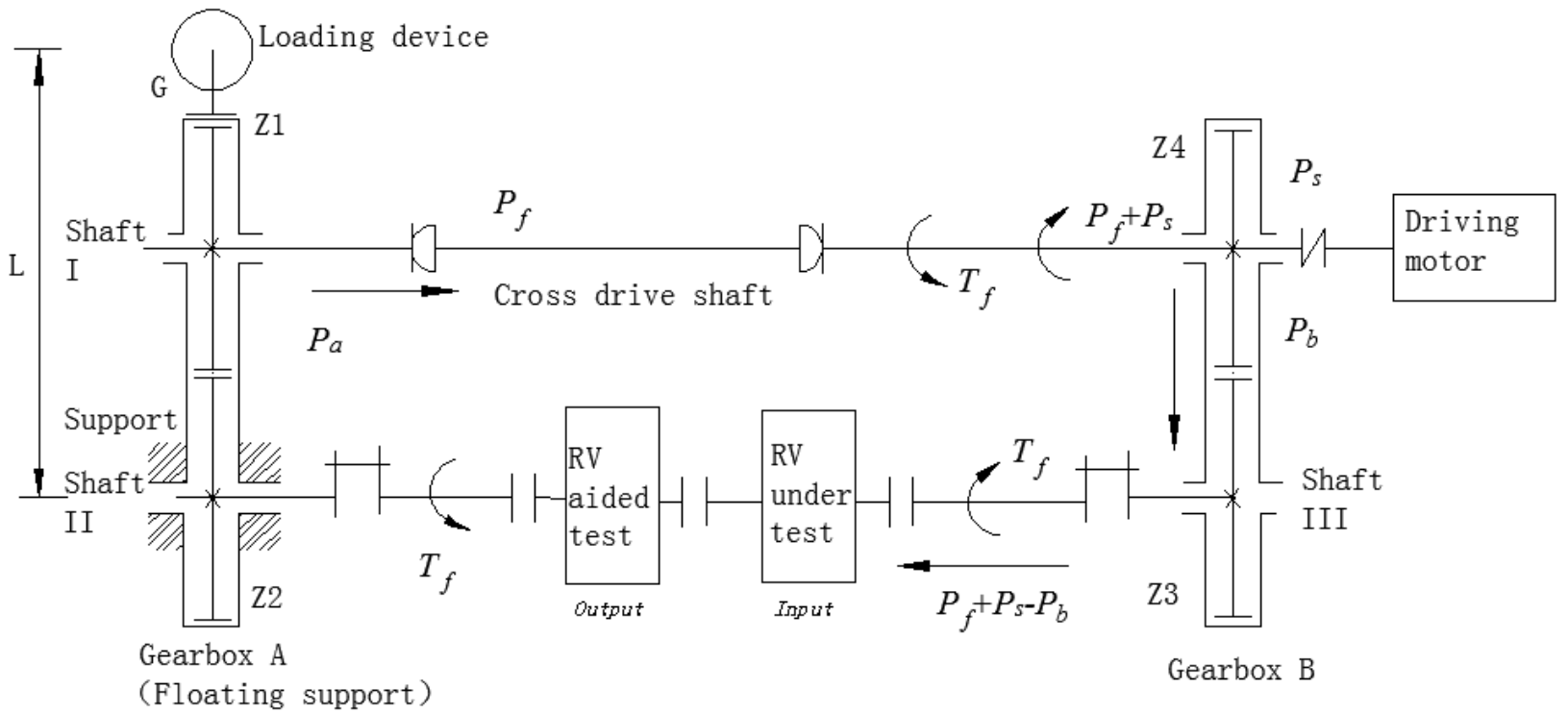

Fig. 4 Power losses in the closed system

The transmission efficiency of gearbox A and B are $\eta_{\mathrm{a}}, \eta_{\mathrm{b}}$. From the above analysis, the power on shaft II is $P_{\mathrm{f}}$, and the power should be $P_{\mathrm{f}} / \eta_{\mathrm{a}}$ on shaft I. Then the output power of gear Z3 in the gearbox B is $P_{\mathrm{f}} /\left(\eta_{\mathrm{a}} \times \eta_{\mathrm{b}}\right)$, available motor power compensation should be provided for:

$$
P_{\mathrm{s}}=\frac{P_{\mathrm{f}}}{\eta_{\mathrm{a}}+\eta_{\mathrm{b}}}-P_{\mathrm{f}}=\frac{P_{\mathrm{f}}}{\eta_{\mathrm{a}}+\eta_{\mathrm{b}}}\left(1-\eta_{\mathrm{a}} \times \eta_{\mathrm{b}}\right)=\frac{P_{\mathrm{f}}}{\eta_{\mathrm{s}}}\left(1-\eta_{\mathrm{s}}\right) .
$$

In this type: $P_{\mathrm{f}}$ is closed power; $\eta_{\mathrm{s}}$ is total transmission efficiency of closed system.

Usually, the compensation power is $1 / 5 \sim 1 / 16$ of the power of the test device. 


\section{Loading method}

The design using weight plate and swing box loading mode. When weight plate was combined with load G (including weight, and the related components quality), swing box counter clockwise, the front gear falling with swing box together at this moment. In this case, the backgear was forced to reverse rotation. At this time, the reaction force of the rear gear action on the front gear also made the front gear to rotate.

The outer meshing gear cannot turn at the same direction. Therefore, the rotation of the oscillating box can only make the shaft I, II and gear Z1, Z2 stress deformation. When the force equilibrium, swing box stop sinking. At this point, the output of the test device is subjected to a load, and the system generates a closed torque $T_{\mathrm{f}}$. According to balance condition of swing box A, there are:

$G \times L=T_{1}+T_{2}$.

This, $T_{1}=T_{2} \times i \times \eta_{\mathrm{a}}$, so, $G=T_{2} \times\left(1+i \times \eta_{\mathrm{a}}\right)$, and the load torque is:

$$
T_{2}=\frac{G \times L}{1+i \times \eta_{\mathrm{a}}} .
$$

In this type: $i$ as the transmission ratio, $i=\mathrm{Z} 1 / \mathrm{Z2} ; \eta_{\mathrm{a}}$ is swing box A transmission efficiency ; $G$ as the equivalent weight of loading plate; $L$ as the loading arm length; $T_{1}, T_{2}$ as torque on the gear $\mathrm{Z} 1, \mathrm{Z} 2$.

\section{Conclusions}

This paper proposes a new design of a new type of power closed test bed aiming at the RV reducer performance test for long periods of time and bigger energy dissipation, such as wear test, the fatigue life test. The test system solves the problem of open power energy loss, energy consumption too large. This test system is simple and efficient. There is great significance for the research on the performance of the RV reducer.

\section{Acknowledgements}

This work was financially supported by the Shandong Province R\&D Key Projects (2014GJJS0401).

\section{References}

[1] Li B: submitted to Journal of Acta Aeronautica ET Astronautica Sinica (2012).

[2] Xiao Zheng-ming, Qin Da-tong and Wu Wen-hui: submitted to Journal of Vibration and Shock (2012).

[3] Shi Xu-dong, Cui Yu-ming and Zhu Jian-feng: submitted to Journal of Manufacturing Automation (2016).

[4] Yan Shi-dang and Liu Zhong-ming: submitted to Journal of Modern Manufacturing Engineering (2015).

[5] Predrag ZIVKOVIC: submitted to Journal of Machine Design (2007).

[6] He-ming Cheng, Tian-cun Yang and Yan-qin Sun: The type and development of large ratio reducer test bed, edited by Joint International Mechanical, Electronic and Information Technology Conference/ Atlantis Publishers, Chongqing, (2015),in press. 